\title{
Proton-Conducting Nanocrystalline Ceramics for High-Temperature Hydrogen Sensing
}

\begin{abstract}
XILING TANG, ZHI XU, ADAM TRONTZ, WENHENG JING, and JUNHANG DONG
The proton-conductive doped ceramic materials, including $\mathrm{SrCe}_{0.95} \mathrm{~Tb}_{0.05} \mathrm{O}_{3-\delta}$ (SCTb), $\mathrm{SrCe}_{0.8} \mathrm{Zr}_{0.1} \mathrm{Y}_{0.1} \mathrm{O}_{3-\delta}(\mathrm{SCZY})$, and $\mathrm{SrZr}_{0.95} \mathrm{Y}_{0.05} \mathrm{O}_{3-\delta}(\mathrm{SZY})$, are synthesized in the forms of nanoparticles and nanocrystalline thin films on sapphire wafers and long-period grating (LPG) fibers. The $\mathrm{H}_{2}$ chemisorption and electrical conductivity of the nanocrystalline SCTb, SCZY, and SZY materials are measured at high temperature with and without the presence of $\mathrm{CO}_{2}$ gas. The resonant wavelength shifts $\left(\Delta \lambda_{\mathrm{R}, \mathrm{H}_{2}}\right)$ of the SCTb, SCZY, and SZY thin-film coated LPGs in response to $\mathrm{H}_{2}$ concentration changes are studied in gas mixtures relevant to coal gasification syngas to evaluate their potential for high-temperature $\mathrm{H}_{2}$ detection. The results show that, at around $773.15 \mathrm{~K}\left(500{ }^{\circ} \mathrm{C}\right), \mathrm{SCTb}$ has the highest $\mathrm{H}_{2}$ sensitivity but the most severe interferences from impurities such as $\mathrm{CO}_{2}$ and $\mathrm{H}_{2} \mathrm{~S}$; SZY has the best chemical resistance to impurities but the lowest $\mathrm{H}_{2}$ sensitivity; and SCZY exhibits high $\mathrm{H}_{2}$ sensitivity with reasonable chemical resistance.
\end{abstract}

DOI: $10.1007 / \mathrm{s} 40553-014-0008-7$

(C) The Minerals, Metals \& Materials Society and ASM International 2014

\section{INTRODUCTION}

THE capability of in situ monitoring of the fuel gas composition is critical to the development of future fossil fuel-based power plants with higher efficiencies, lower operating costs, and reduced emission of pollutants. Although substantial progress has been recently made on the bulk solid state electrochemical and semiconductor hydrogen sensors, ${ }^{[1,2]}$ current sensors are difficult to operate directly in the environments of high temperature, high pressure, corrosive, and strong electromagnetic interference involved in coal-firing power generation processes. ${ }^{[3]}$ Fiber optic chemical sensors (FOCS) are promising for applications in such harsh environments due to a number of advantages such as small size, robustness, immunity to electromagnetic interferences, multiplexing ability, and remote operation capability. ${ }^{[4-6]}$

Recently, we developed a type of refractive index $(n)$ based FOCS by coating long-period grating (LPG) fibers with various ceramic thin films of which the $n$ values are sensitive to specific gases. ${ }^{[7-12]}$ The LPG is a fiber device containing a refractive index module in the core, which couples the transmitting light of certain wavelengths from the guided core mode to propagating cladding modes. ${ }^{[13]}$ The LPG transmission spectrum is characterized by a series of attenuation bands displaying resonant peaks at specific wavelengths $\left(\lambda_{\mathrm{R}}\right)$ given by ${ }^{[14,15]}$

$$
\lambda_{\mathrm{R}}=\left(n_{\mathrm{core}}-n_{\mathrm{cl}, \mathrm{eff}}\right) \Lambda,
$$

XILING TANG and ZHI XU, Ph.D. Candidates, ADAM TRONTZ, Ph.D. Student, WENHENG JING, Postdoc, and JUNHANG DONG, Professor, are with the Department of Chemical Engineering, University of Cincinnati, Cincinnati, OH 45221. Contact e-mail: Junhang.dong@uc.edu

Manuscript submitted October 27, 2013.

Article published online January 25, 2014 where $n_{\text {core }}$ is the effective index of the fundamental core mode, $n_{\mathrm{cl} \text {,eff }}$ is the effective index of the cladding mode, and $\Lambda$ is the grating period typically in a range of 100 to $1000 \mu \mathrm{m}$. The $\lambda_{\mathrm{R}}$ of the LPG undergoes a shift when the refractive index of its surrounding medium changes, because the effective indices of the cladding modes depend on the cladding index and the index of the surrounding. ${ }^{[16,17]}$ The relationship between the surrounding or overcoat refractive index $n_{\mathrm{ov}}$ and the resonant wavelength $\lambda_{\mathrm{R}}$ is described by ${ }^{[18]}$

$$
\frac{d \lambda_{\mathrm{R}}}{d n_{\mathrm{ov}}}=\frac{d \lambda_{\mathrm{R}}}{d n_{\mathrm{cl}, \mathrm{eff}}}-\frac{d n_{\mathrm{cl}, \mathrm{eff}}}{d n_{\mathrm{ov}}}
$$

Thus, LPG-based sensors can be developed by coating materials of which the refractive indices change upon interacting with the analyte molecules. ${ }^{[19,20]}$ The sensitivity of a film-coated LPG sensor, as schematically shown in Figure 1, depends on the gas-film interaction, such as the amount of gas sorption or reaction in the coating material, as well as the magnitude of the difference between the indices of the overcoat $\left(n_{\mathrm{ov}}\right)$ and the fiber cladding $\left(n_{\mathrm{cl}}\right){ }^{[7,11,15,20-22]}$

In our recent work, the proton conductive perovskitetype $\mathrm{Sr}\left(\mathrm{Ce}_{0.8} \mathrm{Zr}_{0.1}\right) \mathrm{Y}_{0.1} \mathrm{O}_{3-\delta}$ thin-film coated LPG sensors were successfully demonstrated for in situ hydrogen sensing at $773.15 \mathrm{~K}\left(500{ }^{\circ} \mathrm{C}\right)$ in multicomponent gases relevant to fossil and biomass gasification syngas. ${ }^{[8,12]}$ At high temperature, the types and populations of the ionic and electronic defects in the perovskite oxides vary with the change of surrounding hydrogen partial pressure due to the following gas-solid reaction ${ }^{[23-25]}$ :

$$
\frac{1}{2} \mathrm{H}_{2}+\mathrm{O}_{O}^{X} \stackrel{k}{\longleftrightarrow} \mathrm{OH}^{\bullet}+\mathrm{e}^{-}
$$

The concentrations of electronic $(n)$ and ionic $\left[\mathrm{OH}^{\bullet}\right]$ defects are dependent of $\mathrm{H}_{2}$ partial pressure $\left(P_{\mathrm{H}_{2}}\right)$ : 

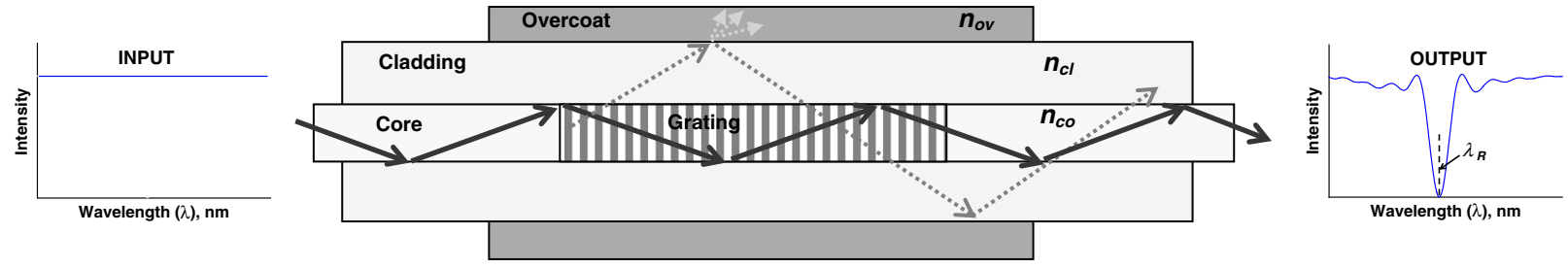

Fig. 1 - Schematic showing the LPG sensor and the transmission spectrum. ${ }^{[8]}$

$$
\left[\mathrm{OH}^{\bullet}\right] n=\sqrt{k} P_{\mathrm{H}_{2}}^{1 / 2}\left[\mathrm{O}_{O}^{X}\right]
$$

where $\left[\mathrm{O}_{O}^{X}\right]$ is the concentration of lattice oxygen ion, which remains nearly constant; and $k$ is the temperature dependent equilibrium constant. The changes in defect composition lead to electrical conductivity and refractive index variations of the ceramic coating that consequently causes resonant wavelength shift $\left(\Delta \lambda_{R}\right)$ for the film-coated LPG sensor. ${ }^{[8,12,25]}$

The performance of a FOCS, in terms of sensitivity, selectivity, and stability, is determined by the type of fiber optic device, detection mechanism, and chemical and physical properties of the sensing film. Since the report of proton conduction in doped $\mathrm{SrCeO}_{3}$ perovskite materials, ${ }^{[26]}$ substantial research works have been performed on developing cerate- and zirconate-based perovskite-type doped ceramics as high-temperature proton/electronmixed conductors. In general, the doped cerates have higher proton conductivity than the doped zirconates, but the latter (e.g., doped-SrZrO $\mathrm{H}_{3}$ ) possess better chemical stability than the former (e.g., doped $\mathrm{SrCeO}_{3}$ ) in hightemperature $\mathrm{CO}_{2}$-containing atmospheres. The gas-sensitive electrical and optical properties of the proton-conductive perovskite-type ceramics can be readily modified by doping with rare earth metal ions. ${ }^{[25]}$ Therefore, significant opportunities exist for the development of ceramic ion conductors for optical and electrical hightemperature gas sensors. In this work, the proton-conducting doped ceramics, including the $\mathrm{SrCe}_{0.95} \mathrm{~Tb}_{0.05} \mathrm{O}_{3-\delta}$ (SCTb), $\mathrm{Sr}\left(\mathrm{Ce}_{0.8} \mathrm{Zr}_{0.1}\right) \mathrm{Y}_{0.1} \mathrm{O}_{3-\delta}(\mathrm{SCZY})$, and $\mathrm{SrZr}_{0.95}$ $\mathrm{Y}_{0.05} \mathrm{O}_{3-\delta}(\mathrm{SZY})$, were synthesized in the forms of nanocrystalline thin films and nanoparticles by a facile polymeric precursor route. The effects of environmental gas on the physical and chemical properties of these nanocrystalline ceramic materials were experimentally investigated to evaluate their potential as high-temperature $\mathrm{H}_{2}$ sensing materials for in situ $\mathrm{H}_{2}$ measurement in conditions relevant to coal and biomass gasification syngas.

\section{EXPERIMENTAL}

\section{A. Material Synthesis}

The SCTb, SCZY, and SZY nanocrystalline thin films were synthesized on the LPG fibers and sapphire substrates by the polymeric precursor route, which include metal-chelated polymeric precursor film coating and thermal treatment steps at relatively low temperatures tolerable to the LPG $\left(<1073.15 \mathrm{~K}\left(800{ }^{\circ} \mathrm{C}\right)^{[8]}\right)$. The LPG was made from single mode silica fibers (Corning ${ }^{\circledR}$ SMF-28 ${ }^{\mathrm{TM}} ; \phi 8.2-\mu \mathrm{m}$ Ge-doped core and $\phi 125-\mu \mathrm{m}$ fused silica cladding) via point-by-point $\mathrm{CO}_{2}$-laser irradiation. ${ }^{[27]}$ The grating segment was $\sim 50 \mathrm{~mm}$ in total length with a $\Lambda$ of $\sim 520 \mu \mathrm{m}$. The precursors for the metal oxide materials are metal ion-chelated polyesters, which were prepared by acid-catalyzed polymerization ${ }^{[28]}$ of metal ion-containing ethylene glycol aqueous solutions using a procedure similar to those reported in the literature. ${ }^{[8,28]}$

In preparation of the $\mathrm{SCTb}$ precursor, an aqueous solution was obtained by dissolving $0.02 \mathrm{~mol}$ of strontium nitrate (Sigma-Aldrich, 99+ pct), $0.019 \mathrm{~mol}$ of cerium nitrate hexahydrate (Aldrich, 99 pct), and $0.001 \mathrm{~mol}$ of terbium nitrate pentahydrate (Aldrich, $99.9 \mathrm{pct}$ ) in $20 \mathrm{~mL}$ DI water. This metal ion solution was subsequently mixed with $40 \mathrm{~mL}$ ethylene glycol (SigmaAldrich, 99 pct) and $0.02 \mathrm{~mol}$ of glycine (Sigma, 99 pct) to form the starting solution for polymerization. The polymerization process was then conducted at $80^{\circ} \mathrm{C}$ for 3 to 4 days in a $125-\mathrm{mL}$ flask with its mouth open for removal of water. After polymerization, the flask was sealed and cooled naturally to room temperature. The resultant polymeric solution was aged for 2 to 3 days before use for film coating.

The precursors for the SCZY and SZY materials were synthesized via the same procedure as described above for $\mathrm{SCTb}$ precursor synthesis but using solutions of different metal ions. The initial aqueous solution for the SZY precursor was obtained by dissolving $0.02 \mathrm{~mol}$ of strontium nitrate (Sigma-Aldrich, 99+ pct), $0.001 \mathrm{~mol}$ of yttrium nitrate hexahydrate (Aldrich, 99.9 pct), and $0.019 \mathrm{~mol}$ of zirconyl chloride octahydrate (SigmaAldrich, 98 pct) in $20 \mathrm{~mL}$ DI water. For the SCZY precursor, the starting aqueous solution contained $4.2326 \mathrm{~g} \mathrm{Sr}\left(\mathrm{NO}_{3}\right)_{2}$ (Sigma, 99 pct), $6.9475 \mathrm{~g} \mathrm{Ce}(\mathrm{N}-$ $\left.\mathrm{O}_{3}\right)_{3} \cdot 6 \mathrm{H}_{2} \mathrm{O}$ (Aldrich, $99 \mathrm{pct}$ ), $0.6445 \mathrm{~g} \mathrm{ZrOCl}{ }_{2} \cdot 8 \mathrm{H}_{2} \mathrm{O}$ (Sigma, 98 pct), 0.7660 g Y $\left(\mathrm{NO}_{3}\right)_{3} \cdot 6 \mathrm{H}_{2} \mathrm{O}$ (Aldrich, 99 pct), and $20 \mathrm{~mL}$ DI water.

The SCTb, SCZY, and SZY films on the LPG fiber surfaces were obtained by coating the polymeric precursor film followed by drying and firing processes. The polymeric precursor was coated onto the fiber by sliding a precursor droplet with a small brush tip over the horizontally suspended LPG segment at a speed of $\sim 1 \mathrm{~cm} / \mathrm{s}$. The coated precursor layer was converted to a metal-oxide film by firing at $823.15 \mathrm{~K}\left(550^{\circ} \mathrm{C}\right)$ for 2 hours in a tube furnace. The film thickness can be varied by repeating the coating-firing process. In this work, all the final metal oxide films on the LPGs were obtained by five times of repeated precursor coating and firing process so that the film thicknesses are similar. The ceramic thin films on the sapphire wafers $(20 \mathrm{~mm} \times$ $20 \mathrm{~mm} \times 0.5 \mathrm{~mm},\langle 001\rangle$, Crystal systems Inc., MA) were prepared by spin-coating of the precursor films followed 
by drying and firing processes. The detailed procedures for precursor coating and firing on both the fiber and sapphire wafers have been reported elsewhere. ${ }^{[8,10]}$ The polymeric precursor films were dried at $373.15 \mathrm{~K}$ $\left(100{ }^{\circ} \mathrm{C}\right)$ and then fired at $823.15 \mathrm{~K}\left(550{ }^{\circ} \mathrm{C}\right)$ in air for 3 hours with the same heating and cooling rates of $5^{\circ} \mathrm{C} /$ min. The resultant SCTb, SCZY and SZY films were further treated by a 30-min annealing process at $973.15 \mathrm{~K}$ $\left(700{ }^{\circ} \mathrm{C}\right)$ to stabilize the microstructure and inhibit further grain growth in the nanocrystalline film during long-term operation at a relatively lower temperature, i.e., $773.15 \mathrm{~K}\left(500{ }^{\circ} \mathrm{C}\right)$ in the present work. ${ }^{[29]}$ The SCTb, SCZY, and SZY nanocrystalline particles were also synthesized for studying high-temperature $\mathrm{H}_{2}$ uptake and chemical stability in different gases. The particles were obtained by drying and firing thick precursor films $(\sim 1 \mathrm{~mm})$ in large crucibles. The conditions for thermal treatments of these particulate samples were the same as that used in the SCTb, SCZY, and SZY film fabrications.

\section{B. Material Characterization}

The SCTb, SCZY, and SZY thin films on the LPG fiber surfaces and sapphire substrates were examined by electron scanning microscopy (SEM) to determine the film thickness. The sapphire-supported thin films were used for electrical conductivity measurement by the conventional four-point method. The grain sizes of the SCTb, SCZY, and SZY nanoparticles were estimated by transmission electron microscopy (TEM). The materials were examined by X-ray diffraction (XRD; PANalytical X'Pert Pro diffractometer, $\mathrm{Cu} K_{\alpha} 1.54060 \AA$ 跬 Bragg-Brentano $\theta-2 \theta$ ) to identify the crystal phases. The Attenuated Total Reflectance (ATR) Fourier transform infrared spectrometry (FTIR) was used in chemical analysis for the SCTb before and after high-temperature treatments in various gas flows. The ATR sample stage used a diamond crystal to collect the reflection intensity over the IR wave number range of 400 to $4000 \mathrm{~cm}^{-1}$. The SCTb samples were also analyzed by X-ray photoelectron spectroscopy (XPS) (Kratos Axis Ultra photoelectron spectrometer; monochromated $\mathrm{Al} \mathrm{K}$ radiation $E=1486.6 \mathrm{eV}$ with a linewidth of $0.2 \mathrm{eV}$ ) to investigate the states of adsorbed sulfur compounds.

\section{C. $\mathrm{H}_{2}$ Chemisorption and Conductivity Measurements}

The high temperature $\mathrm{H}_{2}$ uptakes in the $\mathrm{SCTb}$, SCZY, and SZY nanocrystalline particles were mea- sured by a Chemisorption Analyzer (Micromeritics ASAP 2020). Ultra high purity helium (>99.999 pct, Marathon) was used as sweeping gas for the two-step chemisorption measurement. ${ }^{[30]}$ In the $\mathrm{H}_{2}$ chemisorption measurements, the amount of nanoparticle sample used was $\sim 300 \mathrm{mg}$, and the dwelling time at each partial pressure was 20 minutes, which was found to be sufficient for reaching equilibrium state.

The electrical conductivities of the sapphire-supported SCTb, SCZY, and SZY thin films were measured in atmospheres of controlled compositions by the fourpoint DC method. The electrical conductivity measurement procedure has been described in our previous publications. ${ }^{[31]}$ The sapphire-supported SCTb, SCZY, and SZY thin films were cut by a diamond blade into a rectangular shape with dimensions of $20 \mathrm{~mm} \times 10 \mathrm{~mm}$. A Pt-Rh wire (30 wt pet Rhodium; dia. $=0.003$ in.) was twisted around the specimen and fixed to the sample surface by silver paste. The distance between the two parallel inner leads was $\sim 6 \mathrm{~mm}$. Constant DC current was provided by the potentiostat (Gamry, Reference $600^{\mathrm{TM}}$ ) through the pair of outer leads, and the voltage drop between the pair of inner leads was determined by the voltage probes of the potentiostat. The film conductivity $(\sigma)$ was measured in a temperature range of $723.15 \mathrm{~K}$ to $923.15 \mathrm{~K}\left(450{ }^{\circ} \mathrm{C}\right.$ to $\left.650{ }^{\circ} \mathrm{C}\right)$.

\section{Optical Sensing Test}

The high-temperature gas sensing tests for the filmcoated LPG were performed by an apparatus schematically shown in Figure 2, which is similar to that described in our previous publications. ${ }^{[8,12]}$ The filmcoated LPG sensing segment was hosted in a $1 / 4^{\prime \prime}-$ I.D. stainless steel tube, which was placed horizontally in a tubular furnace $\left( \pm 1.0^{\circ} \mathrm{C}\right)$. The two ends of the tube were connected to the sample gas supply unit and ventilation, respectively. The LPG transmission spectrum, covering a near IR wavelength range of 1510 to $1640 \mathrm{~nm}$, was obtained by sweeping the wavelength of a tunable laser (Agilent 81640A) and detecting the transmitting light using an optical power detector (Agilent $8164 \mathrm{~A}$ ) coordinated by a computer data acquisition system. A wavelength increment of $0.1 \mathrm{~nm}$ and a dwelling time of 1 second at each wavelength point were used in the spectrum scanning. In the tests of single wavelength response, the transmission laser intensity was read at a frequency of $10 \mathrm{~Hz}$. In all measurements, a low flow rate of the sample gas $\left[10 \mathrm{~cm}^{3}(\mathrm{STP}) / \mathrm{min}\right]$ was

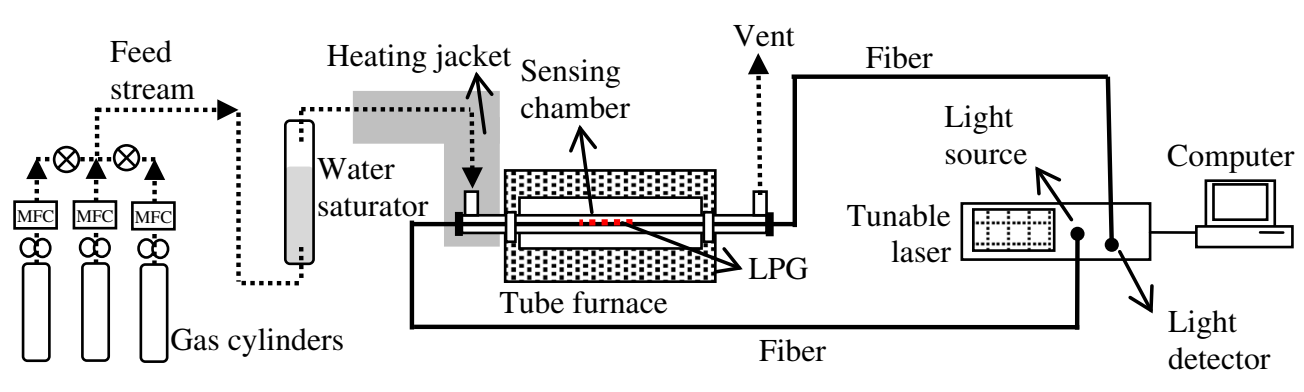

Fig. 2-Schematic diagram of the high temperature optical sensor testing system. 
used to ensure that the gas reached the set temperature when contacting the sensing element. For safety assurance, a $\mathrm{H}_{2} \mathrm{~S}$ absorber was used in the vent line, and a household $\mathrm{CO}$ detector was installed near the sensor testing apparatus.

The temperature dependence of the baseline $\lambda_{\mathrm{R}, \mathrm{N}_{2}}$ is predetermined and represented by the expression of $\left(\lambda_{\mathrm{R}, \mathrm{N}_{2}}\right)_{\mathrm{T}}=\lambda_{\mathrm{R}, \mathrm{N}_{2}}^{0}+\zeta T$ because the values of $\lambda_{\mathrm{R}}$ of LPGs are known to exhibit excellent linear dependence on temperature. The $\zeta$ value was determined experimentally for each film-coated LPG sensor for calibration. The $\zeta$ values were typically $\sim 0.10 \mathrm{~nm} /{ }^{\circ} \mathrm{C}$ in a temperature range of $723.15 \mathrm{~K}$ to $823.15 \mathrm{~K}\left(450{ }^{\circ} \mathrm{C}\right.$ to $\left.550{ }^{\circ} \mathrm{C}\right)$ with minor variations among different LPG sensors. At an operating temperature $T$, the $\Delta \lambda_{\mathrm{R}}$ for a sample gas " $i$ ", $\left(\Delta \lambda_{\mathrm{R}, i}\right)$ is given by ${ }^{[10]}$ :

$$
\Delta \lambda_{\mathrm{R}, i}=\left(\lambda_{\mathrm{R}, i}\right)_{\mathrm{T}}-\left(\lambda_{\mathrm{R}, \mathrm{N}_{2}}\right)_{T},
$$

where $\left(\lambda_{\mathrm{R}, i}\right)_{T}$ is the resonant wavelength in gas $i$ at temperature $T$ and $\left(\lambda_{\mathrm{R}, \mathrm{N}_{2}}\right)_{\mathrm{T}}$ is the reference.

\section{RESULTS AND DISCUSSION}

\section{A. Thin Films and Nanoparticles}

Figure 3 shows SEM images of the cross-sections of SCTb, SCZY, and SZY films on LPG fibers and sapphire wafers. These images show uniform film thicknesses of 450 to $500 \mathrm{~nm}$ on the LPG fiber surfaces and thicknesses of 320 to $350 \mathrm{~nm}$ on the sapphire wafers. The TEM pictures of the powder samples insetted in Figure 3 show that the grain sizes of the as-synthesized SCTb, SCZY, and SZY materials, after the 30 -min annealing at $973.15 \mathrm{~K}\left(700{ }^{\circ} \mathrm{C}\right)$, were about 15 to 25,10 to 20 , and 8 to $12 \mathrm{~nm}$, respectively.

\section{B. $\mathrm{H}_{2}$ Chemisorption and Electrical Conductivity}

The $\mathrm{H}_{2}$ chemisorption on the fresh SCTb, SCZY, and SZY nanoparticle samples measured under $\mathrm{H}_{2}$ partial pressure of $\sim 0.05$ bar (i.e., $\sim 5$ vol pct $\mathrm{H}_{2}$ in Helium at atmospheric pressure; reference pressure $P_{0}=1$ bar) and temperature of $623.15 \mathrm{~K}$ to $873.15 \mathrm{~K}\left(350{ }^{\circ} \mathrm{C}\right.$ to $600{ }^{\circ} \mathrm{C}$ ) is presented in Figure 4(a). For all three materials, the amount of $\mathrm{H}_{2}$ chemisorption increased with increasing temperature, and the $\mathrm{H}_{2}$-uptake values were in the order of $\mathrm{SCTb}>\mathrm{SCZY}>\mathrm{SZY}$. The $\mathrm{H}_{2}-$ uptake data suggest that, based on Eqs. [3] and [4], the defect population, and thus, the electrical and optical properties change in response to $P_{\mathrm{H}_{2}}$ variation would be the largest for SCTb and the smallest for SZY. The temperature dependences of $\mathrm{H}_{2}$ chemisorption also indicate that increasing the operation temperature can enhance the $\mathrm{H}_{2}$ uptake and consequently increase the materials' $\mathrm{H}_{2}$ sensitivity.

However, raising temperature may also induce or accelerate reactions between the solid oxides and other coexisting gases that could introduce sensing interferences and material degradation. In our previous study, gases like $\mathrm{CO}_{2}, \mathrm{H}_{2} \mathrm{O}, \mathrm{CO}$, and $\mathrm{H}_{2} \mathrm{~S}$, which are the major impurities in the coal-derived syngas, were found to cause minimal interferences on the optical response of SCZY-LPG in $\mathrm{H}_{2}$ detection at practically meaningful temperatures around $773.15 \mathrm{~K}\left(500{ }^{\circ} \mathrm{C}\right)$. In this study, the chemisorption isotherms were measured for the SCTb, SCZY, and SZY nanoparticles before and after being exposed to a gas mixture containing 50 pct $\mathrm{CO}_{2}$ and 50 pet $\mathrm{N}_{2}$ at $773.15 \mathrm{~K}\left(500{ }^{\circ} \mathrm{C}\right)$ for 100 hours. The results are presented in Figure 4(b). It can be seen that, after being treated in the $\mathrm{CO}_{2}$ gas, the amount of $\mathrm{H}_{2}$ chemisorption of the $\mathrm{SCTb}$ decreased more severely than did the SCZY; whereas, the $\mathrm{H}_{2}$ chemisorption was virtually unchanged in the $\mathrm{CO}_{2}$-treated SZY. These observations are consistent with the literature findings that, in general, the partial substitution of $\mathrm{Ce}^{4+}$ with $\mathrm{Zr}^{4+}$ in the doped cerates improves the $\mathrm{CO}_{2}$ resistance but compromises $\mathrm{H}_{2}$ sorption capacity and electrical conductivity. ${ }^{[23-25]}$

The stabilities of the SCTb, SCZY, and SZY nanocrystalline materials in $\mathrm{CO}_{2}$ were further evaluated. The freshly made SCTb, SCZY, and SZY particle samples were treated in a gas flow containing 50 pct $\mathrm{CO}_{2}$ and 50 pct $\mathrm{N}_{2}$ at $773.15 \mathrm{~K}\left(500{ }^{\circ} \mathrm{C}\right)$ for 3 hours and then cooled down to room temperature with the gas mixture kept flowing. The XRD patterns of the particle samples before and after the $\mathrm{CO}_{2}$ treatments are shown in Figure 5. For both SCTb and SCZY nanoparticles, the high-temperature $\mathrm{CO}_{2}$ treatment caused formation of carbonates that is likely responsible for the lowering their $\mathrm{H}_{2}$ chemisorption capacities in the $\mathrm{CO}_{2}$-treated nanoparticles. The comparison of changes in XRD peak intensities of the perovskite phase (most noticeably at $2 \theta=28.4^{\circ}$ ) and carbonate phase (peak at $2 \theta=25.1^{\circ}$ ) before and after the $\mathrm{CO}_{2}$ treatment indicated that SCTb was more reactive to $\mathrm{CO}_{2}$ than SCZY. The SZY material had the smallest change in crystal phase that was barely noticeable based on the XRD patterns. It is evident that the SCZY and SZY are chemically more stable than the $\mathrm{SCTb}$ in $\mathrm{CO}_{2}$ gas at high temperature.

The total electrical conductivity $(\sigma)$ of the nanocrystalline SCTb, SCZY, and SZY thin films on sapphire substrates was measured at temperatures from $723.15 \mathrm{~K}$ $\left(450{ }^{\circ} \mathrm{C}\right)$ to $923.15 \mathrm{~K}\left(650{ }^{\circ} \mathrm{C}\right)$ in different atmospheres, including pure helium, air, mixture of 5 pet $\mathrm{H}_{2}$ in Helium, and mixture of 5 pet $\mathrm{H}_{2}$ with 30 pet $\mathrm{CO}_{2}$ in balance Helium. The results are shown in Figure 6.

The SCTb and SCZY films exhibited large increases in electrical conductivity when 5 pct $\mathrm{H}_{2}$ is present in the atmosphere as compared to those in pure $\mathrm{He}$ and air. The addition of 30 pet $\mathrm{CO}_{2}$ into the $\mathrm{H}_{2}$-containing atmosphere caused significant decreases of conductivity for both SCTb and SCZY films. Also, the SCTb film, which had the greatest amount of $\mathrm{H}_{2}$ chemisorption, exhibited the highest conductivity in $\mathrm{H}_{2}$; and the SZY, which had the smallest amount of $\mathrm{H}_{2}$ chemisorption, exhibited the lowest conductivity in $\mathrm{H}_{2}$. All three materials had higher conductivity in air than in pure helium because, when exposing these perovskite-type oxides to oxygen- and hydrogen-containing gases at high temperatures, the following gas-solid reactions take place ${ }^{[32-34]}$. 


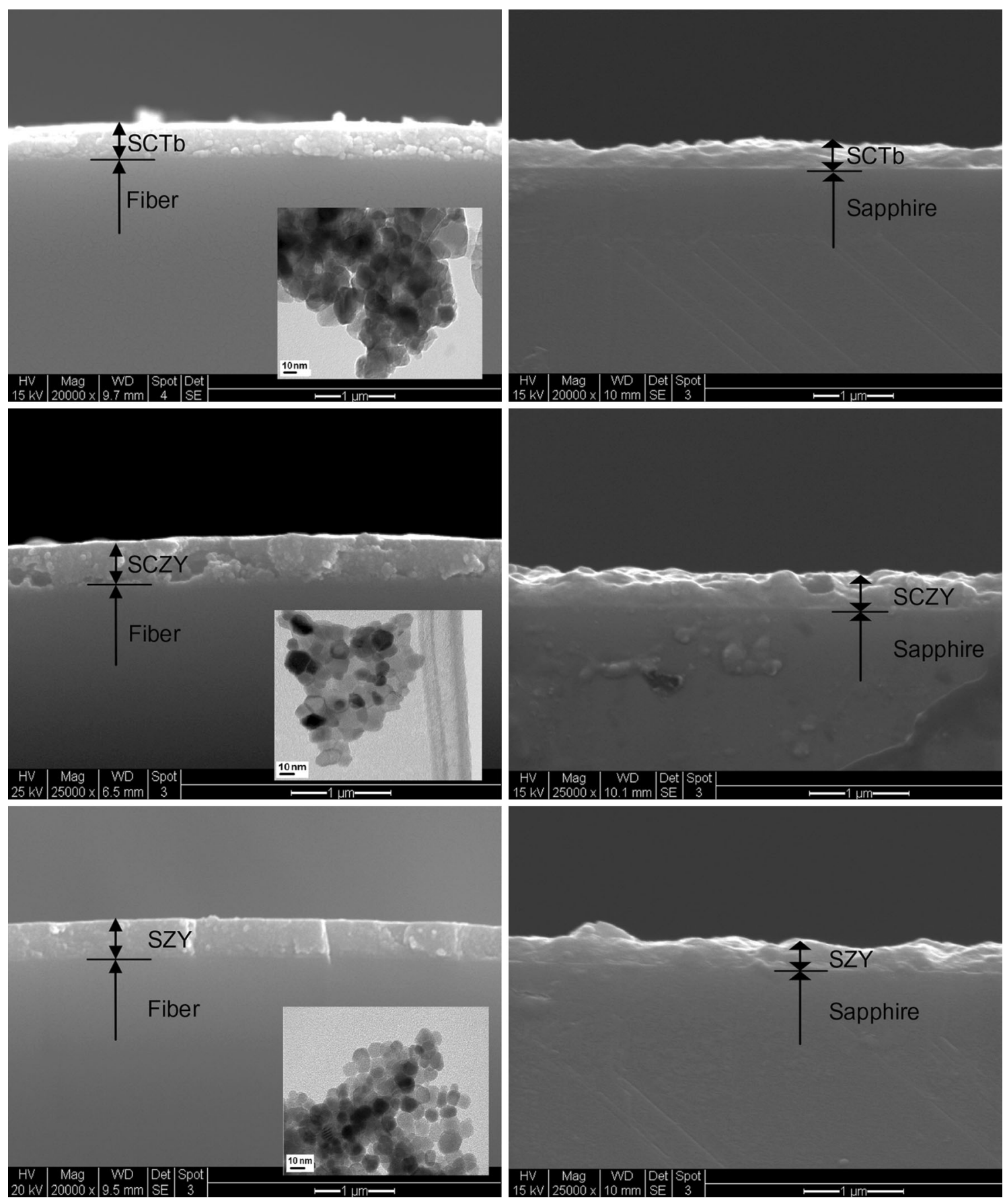

Fig. 3- SEM images of the cross-sections of SCTb, SCZY, and SZY thin films on LPG fibers and sapphire wafers (insetted TEM images show the oxide grains).

$$
\text { in oxygen : } \quad \mathrm{V}_{O}^{\bullet \bullet}+\frac{1}{2} O_{2} \stackrel{k_{1}}{\longleftrightarrow} \mathrm{O}_{O}^{X}+2 h^{\bullet}
$$

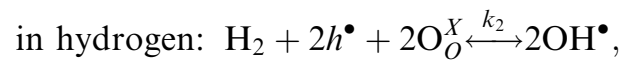

where $k_{1}$ and $k_{2}$ are the reaction equilibrium constants. These reactions cause variations in defect compositions, band gap energy, lattice parameters, and density of the crystalline oxides. Consequently, the electric conductivity as well as the optical refractive index and light absorbance change as a function of the surrounding oxygen or hydrogen partial pressure. Thus, these materials may be also used for gas sensing based on the $\mathrm{H}_{2}$ or $\mathrm{O}_{2}$-partial pressure-dependent electrical conductivity.

The temporal responses of electrical conductivity to switching between a mixture of 2 pet $\mathrm{H}_{2}$ in $\mathrm{He}$ and a mixture of 15 pct Air in $\mathrm{He}$ were performed at $\sim 803.15 \mathrm{~K}\left(530{ }^{\circ} \mathrm{C}\right)$ for the sapphire-supported $\mathrm{SCTb}$, SCZY, and SZY thin films. The results are presented in Figure 7. The electrical conductivities of $\mathrm{SCTb}$ and SCZY thin films responded with significant and revers- 
ible changes to switching between the $\mathrm{H}_{2}$ and air atmospheres. The electrical conductivities of SCTb and SCZY films decreased sharply by about two orders of magnitude when switching from 2 pct $\mathrm{H}_{2}$ to 15 pct air and returned rapidly when switching back to the 2 pct $\mathrm{H}_{2}$ gas. Because of the severe influence of $\mathrm{CO}_{2}$ shown in Figures 6(a) and (b), both SCTb and SCZY are not expected to be successful for $\mathrm{H}_{2}$ sensing in syngas by conductivity monitoring. The SZY film responded to the gas switching with reversible but very small changes in conductivity because of its very low $\mathrm{H}_{2}$ uptake shown in Figure 4. Also, the SZY film exhibited higher conductivity in air than in $\mathrm{H}_{2}$, which is consistent with the findings in Figure 6(c), indicating that SZY is an oxygen

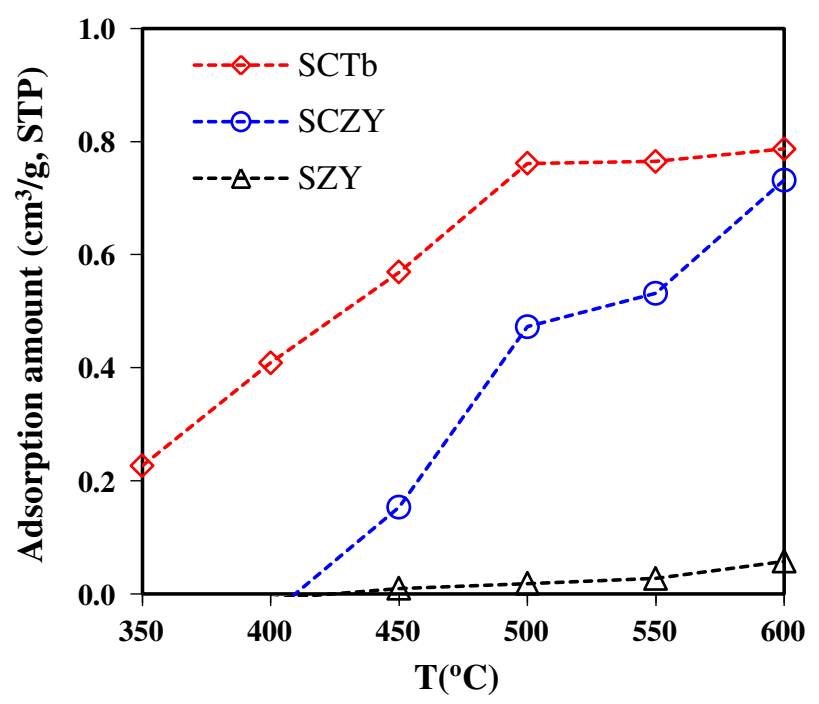

(a)

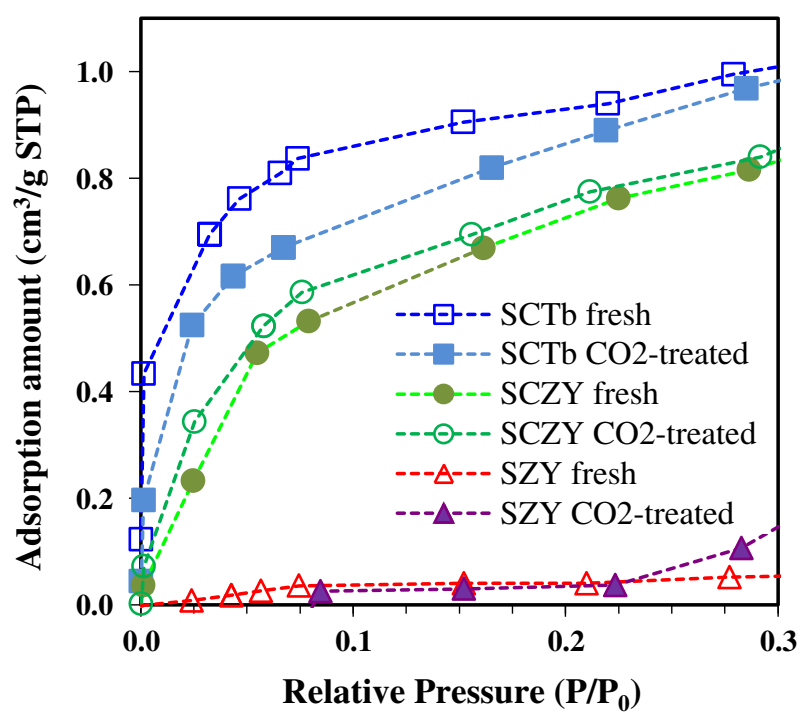

(b)

Fig. 4- $\mathrm{H}_{2}$ uptake on SCTb, SCZY, and SZY nanoparticles: (a) amount of chemisorption as a function of temperature at $P_{\mathrm{H}_{2}}=5 \mathrm{kPa}$, and $(b) \mathrm{H}_{2}$ chemisorption isotherms at $773.15 \mathrm{~K}\left(500^{\circ} \mathrm{C}\right)$ for materials before and after high temperature $\mathrm{CO}_{2}$ treatment $\left(P_{0}=1 \mathrm{bar}\right)$. ion conductor rather than a proton conductor. Although the $\mathrm{H}_{2}$-chemisorption and electrical conductivity dependences on $\mathrm{H}_{2}$ partial pressure of SZY are not seriously affected by $\mathrm{CO}_{2}$, it is not a good material for $\mathrm{H}_{2}$ detection at around $773.15 \mathrm{~K}\left(500{ }^{\circ} \mathrm{C}\right)$ based on conductivity measurement because of its low sensitivity.

\section{Optical Sensing of $\mathrm{H}_{2}$}

The SCTb-LPG, SCZY-LPG, and SZY-LPG sensors were tested for their optical responses, i.e., resonant wavelength shift $\Delta \lambda_{\mathrm{R}}$, as a function of $\mathrm{H}_{2}$ molar fraction in $\mathrm{N}_{2}$ carrier gas and in multicomponent gas mixtures, respectively. The optical sensing tests were performed at $\sim 773.15 \mathrm{~K}\left(500^{\circ} \mathrm{C}\right)$ under ambient pressure. The composition of the multicomponent mixture was adjusted by varying the molar ratio of $\mathrm{H}_{2}: \mathrm{N}_{2}$ in one stream, which was subsequently mixed with a second gas stream of equimolar $\mathrm{CO}$ and $\mathrm{CO}_{2}$ mixture. The final four-component gas mixture was then bubbled through a water vapor saturator at room temperature. The molar composition of the multicomponent gas is $x \mathrm{H}_{2}+(0.57-x)$ $\mathrm{N}_{2}+\left(0.2 \mathrm{CO}+0.2 \mathrm{CO}_{2}+0.03 \mathrm{H}_{2} \mathrm{O}\right)$, where $x$ is the mole fraction of $\mathrm{H}_{2}$ varying from 0 to 0.57 . The $\Delta \lambda_{\mathrm{R}}$ of the sensor in responses to the changes of $\mathrm{H}_{2}$ concentration in the $\mathrm{H}_{2} / \mathrm{N}_{2}$ binary and multicomponent gas flows is presented in Figure 8. The $\mathrm{H}_{2}$ sensing data of SCZY-LPG were taken from previous work. ${ }^{[8]}$

For all three fiber optic sensors, excellent linear relationships between $\Delta \lambda_{\mathrm{R}}$ and $\mathrm{H}_{2}$ concentration $\left(x_{\mathrm{H}_{2}}\right)$ were observed for both binary and multicomponent gas mixtures. The slopes obtained by linearly fitting the data for $\mathrm{H}_{2} / \mathrm{N}_{2}$ binary gas, with the fitted line forced through the origin, are $0.2037 \mathrm{~nm} / \mathrm{kPa}-\mathrm{H}_{2}$ for the SCTb-LPG, $0.1714 \mathrm{~nm} / \mathrm{kPa}-\mathrm{H}_{2}$ for the SCZY-LPG, and $0.0802 \mathrm{~nm} /$ $\mathrm{kPa}-\mathrm{H}_{2}$ for the SZY-LPG. The slope represents the $\mathrm{H}_{2}$ sensitivity defined by the sensor's $\Delta \lambda_{\mathrm{R}}$ in response to a 1 pct change in $\mathrm{H}_{2}$ molar fraction at 1 bar or a change of $1 \mathrm{kPa}$ in $\mathrm{H}_{2}$ partial pressure. Thus, the $\mathrm{H}_{2}$ sensitivity of the three sensors are in the order of SCTb-

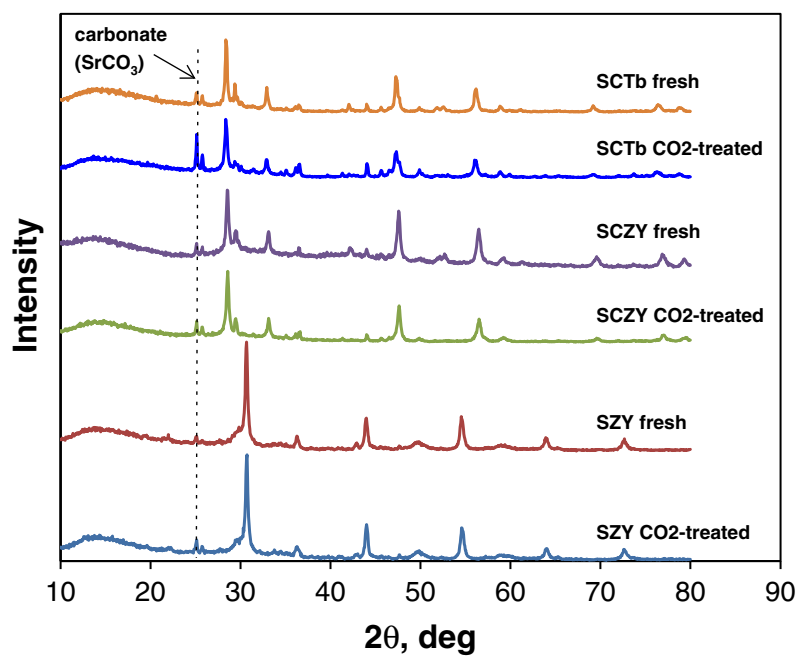

Fig. 5-XRD patterns of the SCTb, SCZY, and SZY particles before and after being treated in 50 pct $\mathrm{CO}_{2}$ (balance $\mathrm{N}_{2}$ ) for $3 \mathrm{~h}$ at $773.15\left(500^{\circ} \mathrm{C}\right)$. 


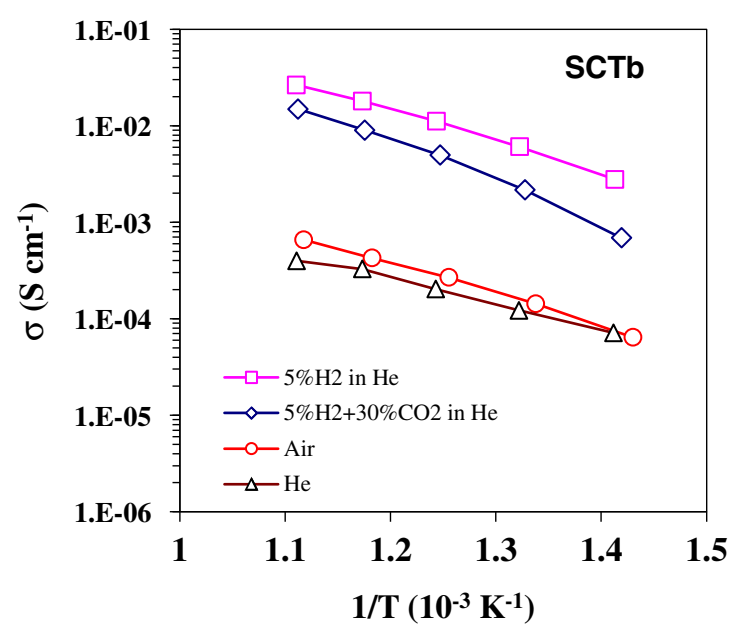

(a)

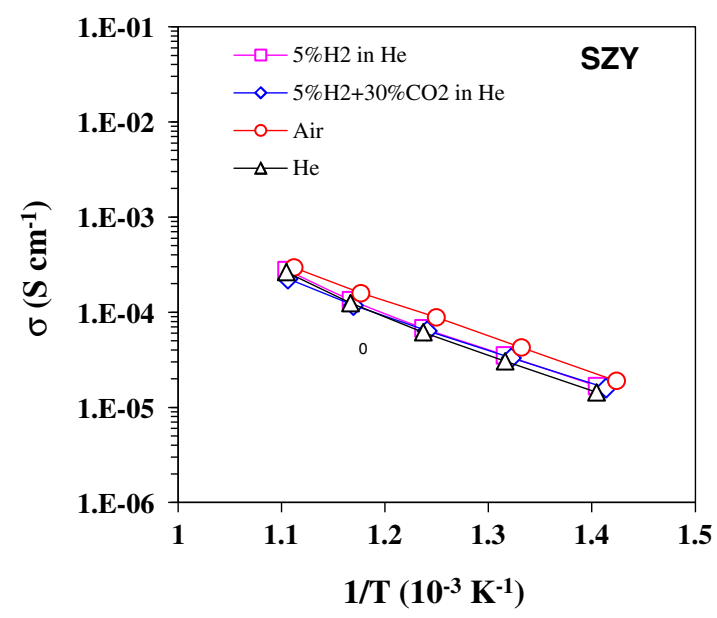

(c)

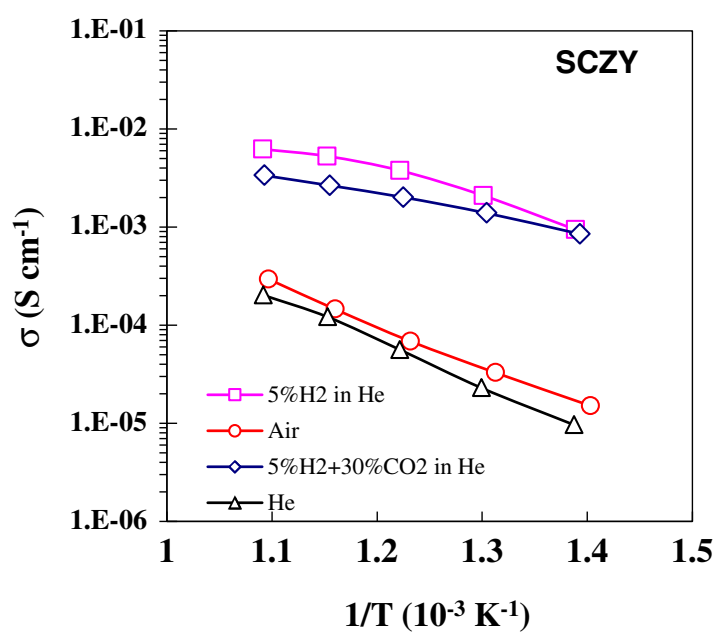

(b)

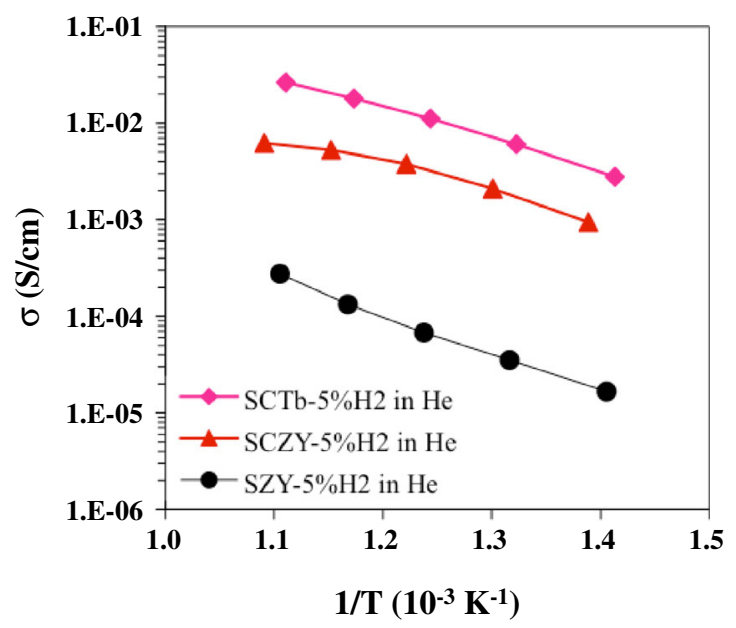

(d)

Fig. 6-Total electrical conductivity of SCTb, SCZY, and SZY films as a function of temperature in different gas atmosphere: $(a)$ SCTb, $(b)$ $\mathrm{SCZY},(c) \mathrm{SZY}$, and $(d)$ comparison of the three films in 5 pct $\mathrm{H}_{2}$.

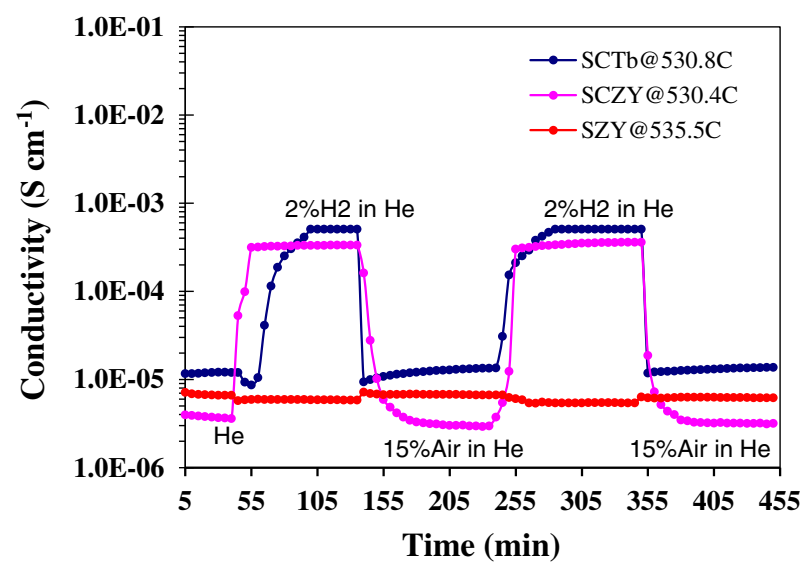

Fig. 7-Temporal responses of total electrical conductivity of the SCTb, SCZY, and SZY thin films to switching gases between a mixture of 2 pct $\mathrm{H}_{2}$ in $\mathrm{He}$ and a mixture of 15 pct Air in He.
LPG $>$ SCZY-LPG > SZY-LPG, which is the same as the order of their $\mathrm{H}_{2}$-uptake and conductivity values. The SCTb-LPG had a significantly smaller response of $0.1181 \mathrm{~nm} / \mathrm{kPa}-\mathrm{H}_{2}$ in the multicomponent gas because of the drastic decease of $\mathrm{H}_{2}$ uptake on SCTb in highconcentration $\mathrm{CO}_{2}$ atmosphere.

The SCZY-LPG showed much more consistent $\Delta \lambda_{\mathrm{R}} \sim x_{\mathrm{H}_{2}}$ correlations between the data in the $\mathrm{H}_{2} / \mathrm{N}_{2}$ binary and multicomponent gases. The slopes were $0.1714\left(\mathrm{~nm} / \mathrm{kPa}-\mathrm{H}_{2}\right)$ and $0.1841\left(\mathrm{~nm} / \mathrm{kPa}-\mathrm{H}_{2}\right)$ in the binary and multicomponent gases, respectively. The refractive index $n$ is directly related to the electrical or dielectric property of the material and is also dependent of the material's density, chemical composition, and microstructure. The slight increase of apparent $\mathrm{H}_{2}$ sensitivity for the SCZY-LPG in the multicomponent gas may be resulted from a combination of the multiple factors rather than from the change of $\mathrm{H}_{2}$ uptake or conductivity. The complex relationships between the 
refractive index and gas-solid reactions as well as their impacts on the sensors' long-term performance are yet to be investigated.

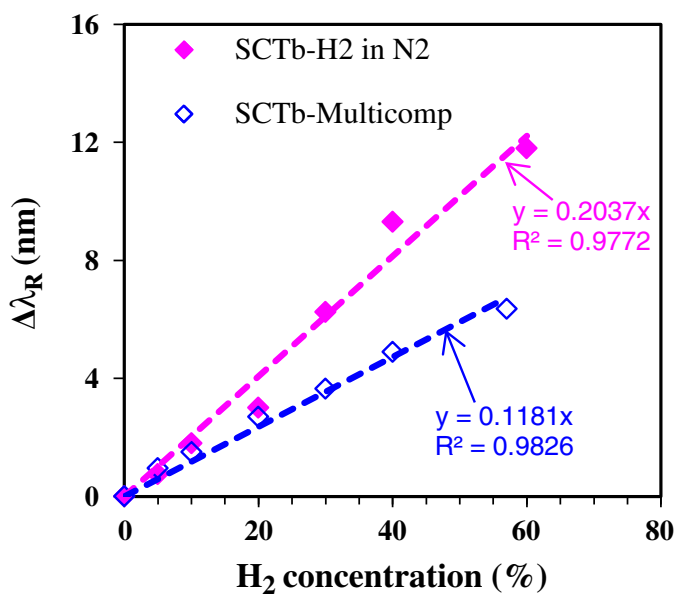

(a)

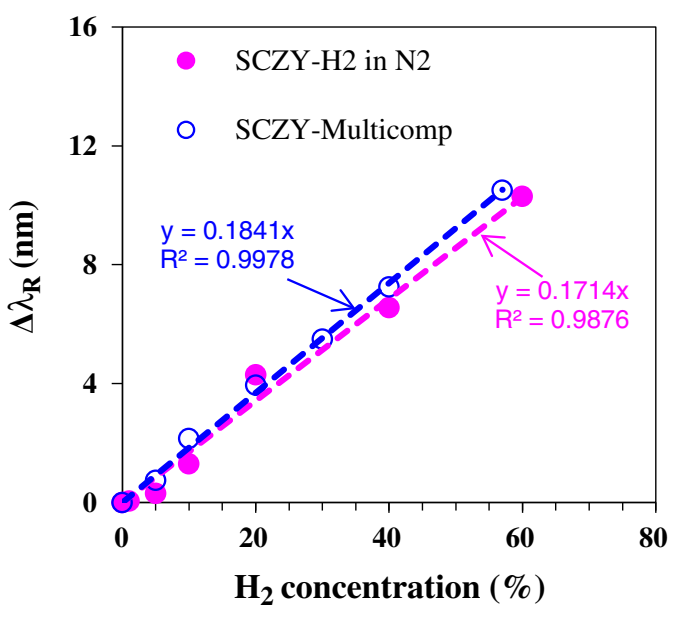

(b)

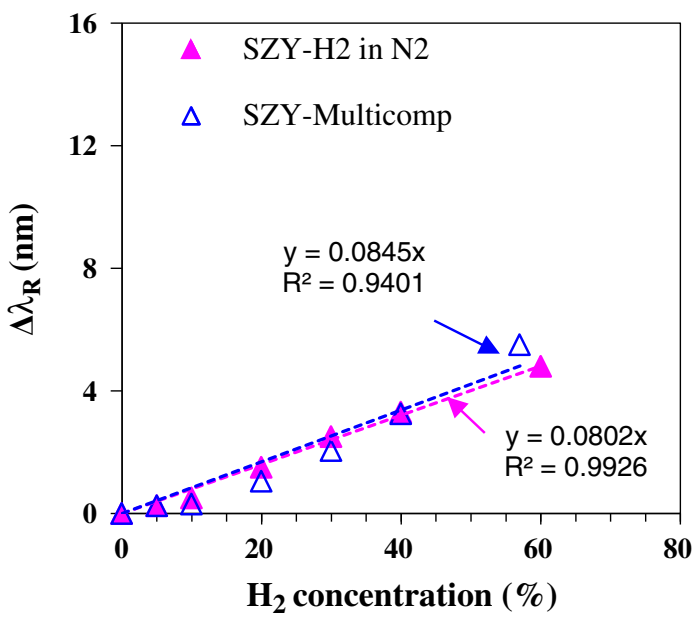

(c)

Fig. 8-Responses of the film-coated LPGs as a function of $\mathrm{H}_{2}$ concentration in binary and multicomponent gas mixtures: (a) SCTbLPG, (b) SCZY-LPG, ${ }^{[8]}$ and (c) SZY-LPG.
The SZY-LPG exhibited the smallest difference in $\Delta \lambda_{\mathrm{R}} \sim x_{\mathrm{H}_{2}}$ correlation between data of the binary and multicomponent gases. The slopes of $\Delta \lambda_{\mathrm{R}} \sim x_{\mathrm{H}_{2}}$ linear correlations for the SZY-LPG were $0.0802\left(\mathrm{~nm} / \mathrm{kPa}-\mathrm{H}_{2}\right)$ and $0.0845\left(\mathrm{~nm} / \mathrm{kPa}-\mathrm{H}_{2}\right)$ in the binary and multicomponent gases, respectively. This very small change of $\mathrm{H}_{2}$ sensitivity in the multicomponent gas is anticipated for SZY-LPG because of the much weaker influence of $\mathrm{CO}_{2}$ on $\mathrm{H}_{2}$ uptake in SZY. Also, in the sensing experiments, two to three times of independent measurements were performed for each sensor, and the average deviations were typically within \pm 10 pct. The slightly greater slopes $\left(\Delta \lambda_{\mathrm{R}} / x_{\mathrm{H}_{2}}\right)$ observed in the multicomponent gases for the SCZY - and SZY-coated LPGs may be attributed to both normal experimental errors and possible additional $\mathrm{H}_{2}$ generated by water gas shift reaction $(\mathrm{CO}+$ $\mathrm{H}_{2} \mathrm{O} \leftrightarrow \mathrm{CO}_{2}+\mathrm{H}_{2}$ ) in the multicomponent stream at high temperature. This postulation can be supported by another fact that even the SCZY-LPG had virtually no appreciable responses to individual $\mathrm{CO}, \mathrm{CO}_{2}$, and $\mathrm{H}_{2} \mathrm{O}$ at $773.15 \mathrm{~K}\left(500{ }^{\circ} \mathrm{C}\right) .{ }^{[8]}$

\section{The Effect of $\mathrm{H}_{2} \mathrm{~S}$}

The SCTb- and SCZY-coated LPGs, which exhibited high sensitivity to $\mathrm{H}_{2}$, were further tested for their response to $\mathrm{H}_{2} \mathrm{~S}$, which is a common impurity in the coal gasification syngas. The experiments were conducted at $773.15 \mathrm{~K}\left(500{ }^{\circ} \mathrm{C}\right)$ and ambient pressure using 3 vol pct $\mathrm{H}_{2} \mathrm{~S}$ gas carried in $\mathrm{N}_{2}$. The temporal response of single wavelength intensity was monitored during switching the sample gas flow between pure $\mathrm{N}_{2}$ and the mixture of 3 pct $\mathrm{H}_{2} \mathrm{~S}$ in $\mathrm{N}_{2}$. Figure 9 shows the changes of the transmission light intensity as a function of time at wavelength of $1612 \mathrm{~nm}$, which was located at about $1 / 3$ of the peak depth to achieve high instrument sensitivity. ${ }^{[11]}$ The SCZY-LPG sensor had no appreciable changes in the transmission light intensity when switching from $\mathrm{N}_{2}$ to the 3 pct $\mathrm{H}_{2} \mathrm{~S}$ gas mixture, which is consistent with our previous findings. ${ }^{[8]}$ The SCTb-LPG

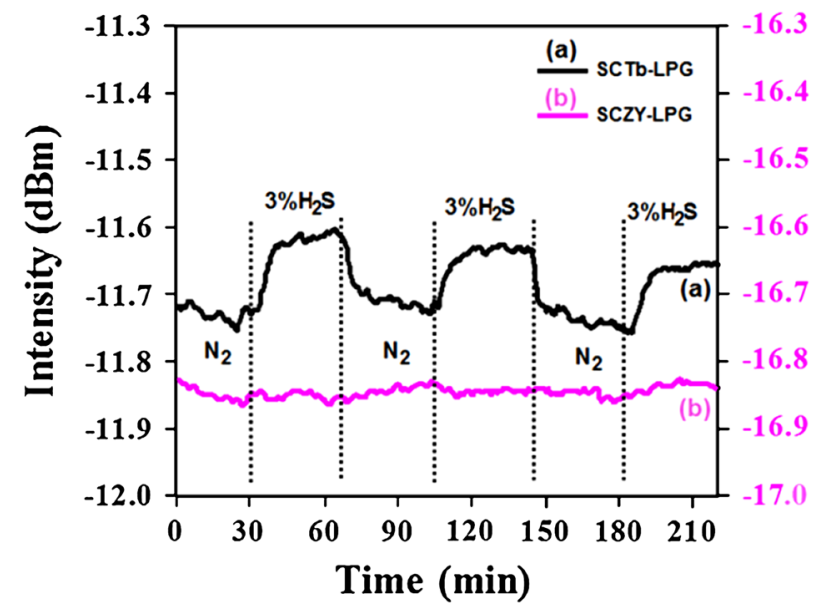

Fig. 9-SCTb-LPG and SCZY-LPG single wavelength responses to switching between pure $\mathrm{N}_{2}$ and 3 pct $\mathrm{H}_{2} \mathrm{~S}$ in $\mathrm{N}_{2}$ at $773.15 \mathrm{~K}$ $\left(500{ }^{\circ} \mathrm{C}\right)$. 


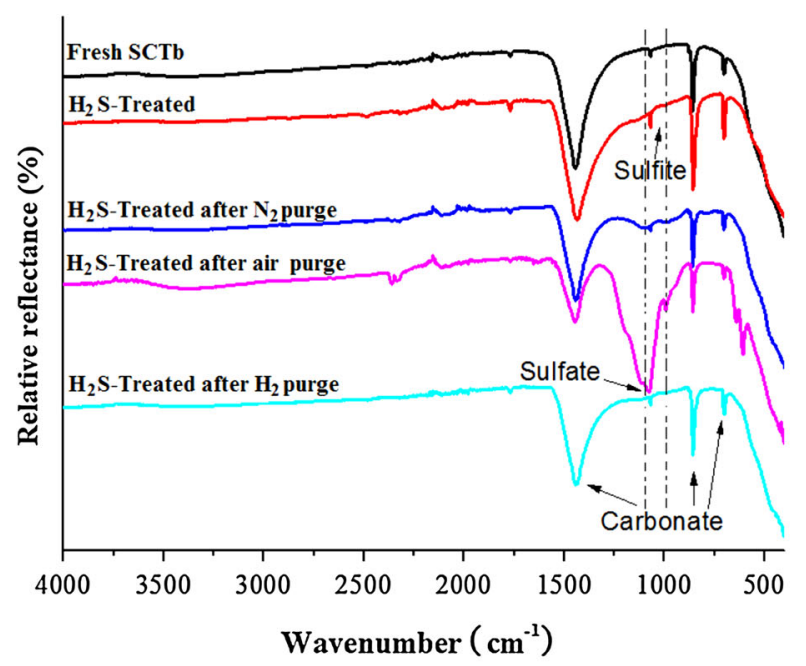

(a)

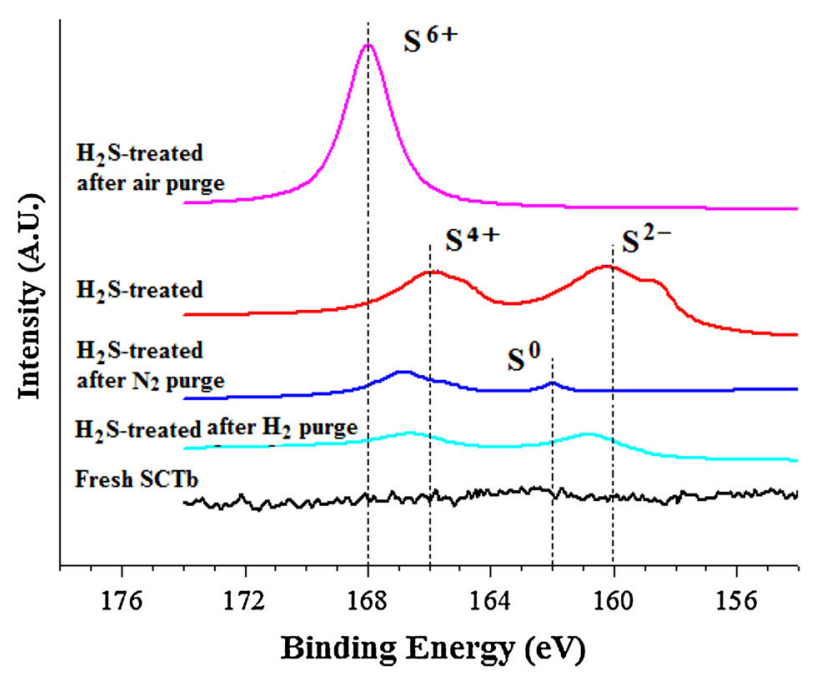

(b)

Fig. 10-FTIR (a) and XPS S2p (b) Spectra of the SCTb nanoparticles before and after treatments in various gases at $773.15 \mathrm{~K}$ $\left(500{ }^{\circ} \mathrm{C}\right)$

sensor had a significant intensity change in response to the gas switch. It is rather interesting that the light intensity change of the SCTb-LPG was reversible when the sample gas was switched back to pure $\mathrm{N}_{2}$.

The chemical composition of the SCTb nanoparticles was examined by ATR FT-IR and XPS before and after high temperature treatments in various gas flows. The fresh $\mathrm{SCTb}$ particle sample was treated in a flow of $\mathrm{N}_{2}-$ carried 3 pct $\mathrm{H}_{2} \mathrm{~S}$ at $773.15 \mathrm{~K}\left(500{ }^{\circ} \mathrm{C}\right)$ for 3 hours and then cooled down to room temperature under the same gas flow. The $\mathrm{H}_{2} \mathrm{~S}$-treated SCTb particles were divided into three parts, which were then treated at $773.15 \mathrm{~K}$ $\left(500{ }^{\circ} \mathrm{C}\right)$ for 3 hours in different gases, including pure $\mathrm{N}_{2}, 20$ pct $\mathrm{H}_{2}$ in $\mathrm{N}_{2}$, and air, respectively. The IR spectra of the SCTb particle samples before and after various gas treatments are presented in Figure 10(a). The vibration bands at 1440,850 , and $690 \mathrm{~cm}^{-1}$ are assigned to carbonates, which existed in the fresh $\mathrm{SCTb}$ in small quantities due to low-temperature firing of the polymeric precursor. After the treatment in 3 pct $\mathrm{H}_{2} \mathrm{~S}$, formation of sulfite $\left(\mathrm{S}^{4+}\right)$ was evidenced by the new vibration bands at 1110 and $995 \mathrm{~cm}^{-1}$. The sulfide $\left(\mathrm{S}^{2-}\right)$ might also exist in the $\mathrm{H}_{2} \mathrm{~S}$-treated sample with its peaks overlapping with those of the carbonates $\left(\sim 830 \mathrm{~cm}^{-1}\right)$ and sulfate $\left(\mathrm{S}^{6+}\right)\left(\sim 1080 \mathrm{~cm}^{-1}\right)$. The sulfate peak intensities increased markedly after the $\mathrm{H}_{2} \mathrm{~S}$-treated samples were further treatment in either pure $\mathrm{N}_{2}$ or air, and the intensity changes were much greater for the air-treated sample than for the $\mathrm{N}_{2}$-treated sample. On the contrary, the peak intensities of sulfite and sulfate are apparently reduced after the $\mathrm{H}_{2} \mathrm{~S}$-treated sample was subsequently treated in the 20 pct $\mathrm{H}_{2}$. These suggest that sulfur of higher oxidation states can be formed on the $\mathrm{H}_{2} \mathrm{~S}$-treated $\mathrm{SCTb}$ by reactions between sulfur of lower oxidation state with either metal oxides (e.g., the strong oxidant $\mathrm{Ce}^{4+}$ ) in $\mathrm{N}_{2}$ flow or with chemisorbed oxygen in air flow. Such continued sulfur oxidation was obviously inhibited in the reducing atmosphere of 20 pct $\mathrm{H}_{2}$.

Figure 10(b) presents the XPS spectra of S2p for the fresh and various gas-treated SCTb samples. The fresh sample had no peaks in the S2p spectra because it was free of sulfur compounds. After exposing to the 3 pct $\mathrm{H}_{2} \mathrm{~S}$ at $773.15 \mathrm{~K}\left(500{ }^{\circ} \mathrm{C}\right)$ for 3 hours, two peaks appeared at $\sim 166.5$ and $160 \mathrm{eV}$, which are assigned to sulfite $\left(\mathrm{SO}_{3}{ }^{2-} ; 166.5 \mathrm{eV}\right)$ and sulfide $\left(\mathrm{S}^{2-} ; 160 \mathrm{eV}\right)$, respectively. The very broad shoulders of these two peaks indicate that sulfate and elemental sulfur $\left(\mathrm{S}^{0}\right)$ might exist as well. In the $\mathrm{H}_{2} \mathrm{~S}$-treated samples, after further treatment at $773.15 \mathrm{~K}\left(500{ }^{\circ} \mathrm{C}\right)$ in air, the sulfide and sulfate peaks disappeared, and a strong new peak of sulfate $\left(\mathrm{SO}_{4}{ }^{2-}\right)$ appeared at $168 \mathrm{eV}$. When the $\mathrm{H}_{2} \mathrm{~S}$ treated $\mathrm{SCTb}$ was subsequently treated in pure $\mathrm{N}_{2}$, the sulfite $\mathrm{S}^{2-}$ peak at $160 \mathrm{eV}$ disappeared, and a new peak of $\mathrm{S}^{0}$ appeared at $162 \mathrm{eV}$; meanwhile the peak originally located at $\sim 166 \mathrm{eV}$ shifted to the middle between 166 and $168 \mathrm{eV}$. These indicate that $\mathrm{S}^{2-}$ was completely oxidized to $\mathrm{S}^{0}$, and $\mathrm{S}^{4+}$ was partially oxidized to $\mathrm{S}^{6+}$. When the $\mathrm{H}_{2} \mathrm{~S}$-treated $\mathrm{SCTb}$ was subsequently treated in the 20 pct $\mathrm{H}_{2}$, the oxidation of $\mathrm{S}^{2-}$ and $\mathrm{S}^{4+}$ to $\mathrm{S}^{0}$ and $S^{6+}$, respectively, is evidenced by the shifts of peaks from $\mathrm{S}^{2-}$ and $\mathrm{S}^{4+}$ positions toward the positions of $\mathrm{S}^{0}$ and $\mathrm{S}^{6+}$, respectively. However, unlike in the results of $\mathrm{N}_{2}$-treated samples where $\mathrm{S}^{2-}$ oxidation to $\mathrm{S}^{0}$ was nearly complete, only part of the $S^{2-}$ was oxidized to $S^{0}$ in the reducing gas of 20 pct $\mathrm{H}_{2}$. The results of XPS analysis are generally consistent with the findings in the FTIR tests. Although accurate quantification of the compositional changes of sulfur compounds is difficult, the drastically reduced peak intensities of the sulfur compounds in the $\mathrm{N}_{2}$ and $\mathrm{H}_{2}$ gas-treated samples demonstrate that reactions involved in chemisorption of $\mathrm{H}_{2} \mathrm{~S}$ in the nanocrystalline $\mathrm{SCTb}$ material are at least partially reversible in inert or reducing atmospheres. The reversibility of $\mathrm{H}_{2} \mathrm{~S}$ chemisorption is perhaps the main reason of the SCTb-LPG's reversible optical responses to gas switching between the 3 pct $\mathrm{H}_{2} \mathrm{~S}$ and pure $\mathrm{N}_{2}$. However, the $\mathrm{H}_{2} \mathrm{~S}$-caused change of output light intensity appeared to decrease gradually over time in Figure 9. This decrease of $\mathrm{H}_{2} \mathrm{~S}$ sensitivity was most likely caused by the very slow thermal-drift of baseline spectrum and the 
incomplete desorption of the chemically adsorbed sulfur compounds in the $\mathrm{H}_{2} \mathrm{~S}$-free gases as indicated by the FTIR and XPS results in Figure 10.

\section{CONCLUSIONS}

The SCTb, SCZY, and SZY nanocrystalline particles and thin films were synthesized. At around $773.15 \mathrm{~K}$ $\left(500{ }^{\circ} \mathrm{C}\right.$ ), the materials showed $\mathrm{H}_{2}$ uptake and electrical conductivity in the order of $\mathrm{SCTb}>\mathrm{SCZY}>\mathrm{SZY}$. Their electrical conductivity exhibited reversible changes in response to switching surrounding gas between $\mathrm{H}_{2}$ containing and air-containing helium. The $\mathrm{H}_{2}$ uptake and conductivity were found to decrease for all three materials in the presence of $\mathrm{CO}_{2}$, which caused carbonate formation in the solid phase. The undesirable influences of $\mathrm{CO}_{2}$ on $\mathrm{H}_{2}$ sorption and conductivity were most severe on SCTb and quite minimal on SZY. The SCTb, SCZY, and SZY nanocrystalline thin-film coated LPG sensors exhibited excellent linear relationships between their resonant wavelength shift $\left(\Delta \lambda_{\mathrm{R}}\right)$ and $\mathrm{H}_{2}$-concentration in surrounding gases at $\sim 773.15 \mathrm{~K}\left(500{ }^{\circ} \mathrm{C}\right)$. The $\mathrm{SCTb}$ LPG exhibited the highest sensitivity for $\mathrm{H}_{2}$ detection but had serious interference from $\mathrm{CO}_{2}$; the SZY-LPG showed the lowest $\mathrm{H}_{2}$ sensivity but had almost no interference from $\mathrm{CO}_{2}$; the SCZY-LPG had high $\mathrm{H}_{2}$ sensitivity and small $\mathrm{CO}_{2}$ interference. The SCZY-LPG was also found to have no appreciable responses to $\mathrm{H}_{2} \mathrm{~S}$ at $773.15 \mathrm{~K}$ $\left(500{ }^{\circ} \mathrm{C}\right)$ that is highly desirable for practical applications, because $\mathrm{H}_{2} \mathrm{~S}$ is a common impurity in coal-derived syngas. The SCTb-LPG showed reversible response to switching gas between pure $\mathrm{N}_{2}$ and $\mathrm{N}_{2}$ containing 3 pct $\mathrm{H}_{2} \mathrm{~S}$. FTIR and XPS examinations of the SCTb particles treated by various gases revealed that chemisorption of $\mathrm{H}_{2} \mathrm{~S}$ on the nanocrystalline SCTb is partially reversible and the adsorbed sulfur could be of different valences in different atmospheres, i.e., oxidizing, reducing, and inert.

Results of this study indicate that the proton conducting nanocrystalline ceramic materials are potentially useful for developing high temperature fiber optic sensors for $\mathrm{H}_{2}$ measurement in fossil and biomassderived syngas. At around $773.15 \mathrm{~K}\left(500{ }^{\circ} \mathrm{C}\right)$, the SCZY may be the best among the three tested materials for $\mathrm{H}_{2}$ detection in the syngas streams because of its high $\mathrm{H}_{2}$ sensitivity and relatively low interferences from other gases. It should be pointed out that chemisorption of $\mathrm{H}_{2}$ and other gases on the metal oxides can be significantly affected by the operation temperature. It is anticipated that impurity interferences can be reduced while maintaining a good $\mathrm{H}_{2}$ sensitivity by lowering the operating temperature for $\mathrm{SCTb}$; and in contrast, the $\mathrm{H}_{2}$ sensitivity might be enhanced while maintaining good chemical resistance to impurity gases by raising the operation temperature for SZY. Our future investigation will be focused on understanding the temperature dependence of the gas-solid reactions, understanding the reaction and chemisorption kinetics, and improving the sensing materials by doping modification and optimization for high sensitivity and selectivity/ stability.

\section{ACKNOWLEDGMENTS}

This material is based upon work supported by the U.S. Department of Energy within the National Energy Technology Laboratory (grant numbers: DE-NT000 8062 and DE-FE0012272).

\section{REFERENCES}

1. E. Comini: Anal. Chim. Acta, 2006, vol. 568 (1-2), pp. 28-40.

2. S. Akbar, P. Dutta, and C. Lee: Int. J. Appl. Ceram. Technol., 2006, vol. 3 (4), pp. 302-311

3. B.T. Chorpening, D. Tucker, and S.M. Maley: IEEE Sensors, 2004, vol. 3, pp. 1153-56.

4. D.S. Blair and J. Bando: Environ. Sci. Technol., 1998, vol. 32 (2), pp. 294-98.

5. A.K. Sharma and B.D. Gupta: Nanotechnology, 2006, vol. 17 (1), pp. 124-31.

6. X. Wang and O.S. Wolfbeis: Anal. Chem., 2013, vol. 85 (2), pp. 487-508.

7. J. Zhang, X. Tang, J. Dong, T. Wei, and H. Xiao: Opt. Express, 2008, vol. 16 (11), pp. 8317-23.

8. X. Tang, K. Remmel, X. Lan, J. Deng, H. Xiao, and J. Dong: Anal. Chem., 2009, vol. 81 (18), pp. 7844-48.

9. J. Zhang, J. Dong, T. Wei, and H. Xiao: Sensors Actuators B, 2009, vol. 135 (2), pp. 420-25.

10. K. Remmel, H. Jiang, X. Tang, J. Dong, X. Lan, and H. Xiao: Sensors Actuators B, 2011, vol. 160 (1), pp. 533-41.

11. X. Tang, J. Provenzano, Z. Xu, J. Dong, H. Guan, and H. Xiao: J. Mater. Chem., 2011, vol. 21 (1), pp. 181-86.

12. H. Jiang, R. Yang, X. Tang, A. Burnett, X. Lan, H. Xiao, and J. Dong: Sensors Actuators B, 2013, vol. 177, pp. 205-212.

13. A.M. Vengsarkar, P.J. Lemaire, J.B. Judkins, V. Bhatia, T. Erdogan, and J.E. Sipe: J. Lightwave Technol., 1996, vol. 14, pp. 58-65.

14. T.J. Erdogan: Lightwave Technol., 1997, vol. 15 (8), pp. 1274-94.

15. N.D. Rees, S.W. James, R.P. Tatam, and G.J. Ashwell: Opt. Lett., 2002, vol. 27 (9), pp. 686-88.

16. X. Shu and L. Zhang: J. Lightwave Technol., 2002, vol. 20 (2), pp. 255-66.

17. D.B. Stegall and T. Erdogan: IEEE Photonics Technol. Lett., 1999, vol. 11 (3), pp. 343-45.

18. V. Bhatia: Opt. Express, 1999, vol. 4 (11), pp. 457-66.

19. A. Cusano, P. Pilla, L. Contessa, A. Iadicicco, S. Campopiano, A. Cutolo, M. Giordano, and G. Guerra: Appl. Phys. Lett., 2005, vol. 87 (23), p. 234105.

20. Z. Gu, Y. Xu, and K. Gao: Opt. Lett., 2006, vol. 31 (16), pp. 2405-07.

21. T.J. Erdogan: J. Opt. Soc. Am., 1997, vol. 14 (8), pp. 1760-67.

22. A. Cusano, A. Iadicicco, P. Pilla, L. Contessa, S. Campopiano, A. Cutolo, and M. Giordano: Opt. Express, 2006, vol. 14 (1), pp. 19-34.

23. Y. Liu, X. Tan, and K. Li: Catal. Rev., 2006, vol. 48 (2), pp. 14598.

24. J.W. Phair and S.P.S Badwal: Ionics, 2006, vol. 12 (2), pp. 103115.

25. E. Fabbri, D. Pergolesi, and E. Traversa: Chem. Soc. Rev., 2010, vol. 39 (11), pp. 4355-69.

26. H. Iwahara, T. Esaka, H. Uchida, and N. Maeda: Solid State Ionics, 1981, vols. 3-4, pp. 359-63.

27. Y. Li, T. Wei, J.A. Montoya, S.V. Saini, X. Lan, X. Tang, J. Dong, and H. Xiao: Appl. Opt., 2008, vol. 47 (29), pp. 5296-5304.

28. H.U. Anderson, M.M. Nasrallah, and C.C. Chen: U.S. Patent, No. 5,494,700, 1996.

29. J. Dong, M.Z. Hu, E.A. Payzant, T.R. Armstrong, and P.F. Becher: J. Nanosci. Nanotechnol., 2002, vol. 2 (2), pp. 161-69.

30. Z. Tang, J. Monroe, J. Dong, T.M. Nenoff, and D. Weinkauf: Ind. Eng. Chem. Res., 2009, vol. 48 (5), pp. 2728-33.

31. M. Price, J. Dong, X. Gu, S.A. Speakman, E.A. Payzant, and T.M. Nenoff: J. Am Ceram. Soc., 2005, vol. 88 (7), pp. 1812-18.

32. H. Uchida, N. Maeda, and H. Iwahara: Solid State Ionics, 1983, vol. 11 (2), pp. 117-24.

33. T. Hibino, K. Mizutani, T. Yajima, and H. Iwahara: Solid State Ionics, 1992, vol. 58 (1-2), pp. 85-88.

34. J. Guan, S.E. Dorris, U. Balachandran, and M.J. Liu: Electrochem. Soc., 1998, vol. 145 (5), pp. 1780-86. 